\title{
Clinical Manifestations and Prognosis of Benign Paroxysmal Positional Vertigo according to Etiology
}

\author{
Wook Jang ${ }^{1}$ D , Jung-Woo Shin ${ }^{1}$, Sang Woo Kim ${ }^{1}$, Do Hyung Kim ${ }^{1}$, Chang Gun Cho ${ }^{1,2}$, \\ Seok-Won Park ${ }^{1,2}$, Yun-Sung Lim ${ }^{1,2}$, Bo Hae Kim ${ }^{1,2}$, and Joo Hyun Park ${ }^{1,2} \mathbb{D}$ \\ ${ }^{I}$ Department of Otorhinolaryngology-Head and Neck Surgery, College of Medicine, Dongguk University, Ilsan Hospital, Goyang; and \\ ${ }^{2}$ Sensory Organ Research Institute, College of Medicine, Dongguk University, Gyeongju, Korea
}

\section{발생 원인에 따른 양성돌발성두위현훈의 임상양상과 예후}

장 욱 $^{1} \cdot$ 신정우 ${ }^{1} \cdot$ 김상우 $^{1} \cdot$ 김도형 $^{1} \cdot$ 조창건 ${ }^{1,2} \cdot$ 박석원 $^{1,2} \cdot$ 임윤성 $^{1,2} \cdot$ 김보해 ${ }^{1,2} \cdot$ 박주현 $^{1,2}$

동국대학교 의과대학 일산병원 이비인후-두경부외과학교실, ${ }^{1}$ 동국대학교 의과대학 감각기관연구소 ${ }^{2}$

\author{
Received October 16, 2020 \\ Revised January 30,2021 \\ Accepted February 9, 2021 \\ Address for correspondence \\ Joo Hyun Park, MD, PhD \\ Department of Otorhinolaryngology- \\ Head and Neck Surgery, \\ College of Medicine, \\ Dongguk University, Ilsan Hospital, \\ 27 Dongguk-ro, Ilsandong-gu, \\ Goyang 10326, Korea \\ Tel $+82-31-961-7436$ \\ Fax $+82-31-961-7427$ \\ E-mail parkzzu19@naver.com
}

Background and Objectives This work investigates the clinical characteristics of benign paroxysmal positional vertigo (BPPV) according to etiology by comparing idiopathic BPPV (iBPPV), BPPV occurring after head trauma (tBPPV) and BPPV associated with idiopathic sudden sensory neural hearing loss (sBPPV).

Subjects and Method A total of 869 patients who were diagnosed and treated for BPPV were reviewed retrospectively. Patients were divided into three groups according to the probable etiology of BPPV: iBPPV vs. tBPPV vs. sBPPV. We investigated and compared demographics, the affected sides and canals, the number of canalith repositioning procedure (CRP) performed to achieve successful reposition, canal conversion and recurrence among the three groups. Among the three groups, BPPV patients who performed caloric test and/or video head impulse test (vHIT) were additionally evaluated and compared.

Results The iBPPV group $(n=787)$ had greater female preponderance $(72 \%, 567 / 787)$ than the tBPPV $(\mathrm{n}=51)$ and sBPPV groups $(\mathrm{n}=31, p<0.001)$. The mean number of CRPs needed for successful repositioning in the iBPPV group $(1.40 \pm 0.03)$ was significantly $(p<0.001)$ lower than that in the tBPPV and sBPPV groups $(2.04 \pm 0.24$ and $2.45 \pm 0.36)$. There was no difference between the tBPPV and sBPPV groups. Recurrence rate was not significantly different among three groups ( $14.6 \%$ vs. $17.7 \%$ vs. $16.2 \%$ ) statistically. The presence of canal paresis and abnormal results of vHIT test were not related with a greater number of CRPs required and recurrence. Conclusion More CRPs were required for successful repositioning in the tBPPV and sBPPV patients than in the iBPPV patients and there was no difference between tBPPV and sBPPV patients. Recurrence rate was not different among the three groups. This information may be helpful for clinicians in counselling and managing BPPV patients.

Korean J Otorhinolaryngol-Head Neck Surg 2022;65(1):18-23

Keywords Benign paroxysmal positional vertigo; Recurrence; Sudden hearing loss; Trauma.

\section{서 론}

양성돌발성두위현훈(benign paroxysmal positional ver- tigo, BPPV)은 말초성 어지럼 질환 중 가장 흔하게 발생하는 질환이며, 자세 변화 및 머리의 움직임에 따라 유발된다. 중이 내에 위치한 난형낭에서 탈락된 이석이 반고리관 내로 들어가

This is an Open Access article distributed under the terms of the Creative Commons Attribution Non-Commercial License (https://creativecommons.org/licenses/by-nc/4.0) which permits unrestricted non-commercial use, distribution, and reproduction in any medium, provided the original work is properly cited. 
면서 어지럼증이 발생하며, 자세 변화나 머리의 움직임에 따라 특징적인 안진이 유발되는 것을 확인하여 진단할 수 있다.,2)

$\mathrm{BPPV}$ 의 경우 평생 발생률은 $2.4 \%$ 이고, 연간 발생률은 $0.6 \%$ 이다. 또한 50 60대에서 가장 흔히 발생하며, 남녀의 성비는 1:2 1:3으로 여성에서 더 많이 발생한다. ${ }^{3)} \mathrm{BPPV}$ 는 특별한 원 인을 찾을 수 없는 경우가 전체의 $70 \%$ 정도로 대부분이지만, 돌발성난청, 메니에르병, 전정신경염 등 다른 질환과 동반되 거나, 두부 외상, 수술 등에 의해서도 발생할 수 있다. ${ }^{4-6)}$ 이차 성 $\mathrm{BPPV}$ 의 원인으로는 두부 외상 및 내이 질환이 가장 많은 비중을 차지하며,") 외상에 의한 이차성 BPPV는 전체의 8.5 $20.0 \%$ 를 차지한다고 알려져 있다. ${ }^{8)}$ 그리고 외상에는 두부 외 상, 경부 채찍질 손상(whiplash injury) 그리고 두경부 수술 등이 포함된다. ${ }^{9-11)}$

$\mathrm{BPPV}$ 의 치료는 일차적으로 원인 반고리관에 따라 이석정 복술(canalith repositioning procedure, $\mathrm{CRP}$ ) 시행을 권고 하고, 증상이 경미한 경우 혹은 $\mathrm{CRP}$ 를 시행하기 어려운 경우 오심 및 구토에 대한 대증치료를 하며 경과관찰을 할 수 있 다. ${ }^{12-14)}$ 이전의 대부분의 연구들에서 두부 외상 후 발생하는 경우 특발성에 비해 회복까지의 CRP 시행 횟수가 많은 것으 로 보고하고 있다. ${ }^{915)}$ 치료 후에도 두부 외상 후에 BPPV가 발 생할 경우 특발성 BPPV보다 더 높은 재발률을 보인다. ${ }^{15)}$ 또 한, 돌발성난청의 경우에도 BPPV가 동반될 수 있는데, 전체 돌발성난청 환자의 $12.7 \%$ 에서 $\mathrm{BPPV}$ 를 동반하는 것으로 보고 되었다. ${ }^{16)}$ 일반적으로 돌발성난청과 동반될 경우 특발성 $\mathrm{BPPV}$ 보다 재발이 잦고, 병의 경과가 길며, 더 나쁜 예후를 가진다고 알려져 있다. 2,16,17)

대부분의 연구들에서 이차성 $\mathrm{BPPV}$ 의 경우 특발성보다 $\mathrm{CRP}$ 시행 시 치료의 결과가 비슷하거나 낮은 것으로 알려져 있다. ${ }^{10)}$ 특발성 $\mathrm{BPPV}$ 와 돌발성난청과 동반된 경우 및 외상 후에 발생한 경우에 따라 각각을 비교한 연구는 있지만, ${ }^{49}$ 이 차성 $\mathrm{BPPV}$ 환자들을 비교하거나, 세 가지 원인들을 동시에 비교한 연구는 많지 않다. 이에 본 연구에서 같은 기간 내에 발생한 $\mathrm{BPPV}$ 환자를 특발성 $\mathrm{BPPV}$, 외상 후에 발생한 $\mathrm{BPPV}$, 그리고 돌발성난청과 동반된 $\mathrm{BPPV}$, 세 가지 원인으로 하여 각각의 임상양상과 치료까지의 $\mathrm{CRP}$ 횟수, 재발률 등에 대해 분석하였다.

\section{대상 및 방법}

\section{대 상}

2015년 3월 2020년 5월까지 본원 이비인후-두경부외과에 어지럼증을 주소로 내원하여, $\mathrm{BPPV}$ 로 진단 받고, $\mathrm{CRP}$ 를 시 행하여, 치료 경과를 평가할 수 있는 869명의 성인 환자를 대
상으로 의무기록을 후향적으로 분석하였다. 이러한 의무기록 의 분석은 인증된 연구윤리심의위원회(Institutional Review Board)의 승인을 받은 후에 진행되었다(No. DUIH 202006-012). 진단 시에는 2017년 American Academy of Otolaryngology-Head and Neck Surgery Foundation(AAO$\mathrm{HNSF}$ ) 가이드라인에 따라 머리굴림검사(roll test), bow-lean 검사와 Dix-Hallpike test로 자세변화에 따라 유발되는 안진 을 확인하여 진단하였다. ${ }^{18,19)}$ 환자 중 메니에르병, 전정신경염, 람제이-헌트 증후군(Ramsay-Hunt syndrome) 등 어지럼증 을 일으킬 수 있는 다른 원인 질환을 가진 경우, 중추성 현훈 으로 진단된 경우, 체위안진검사에서 명확한 안진이 확인되 지 않은 경우, $\mathrm{CRP}$ 치료를 시행하지 않은 경우, 치료를 하여 도 호전되지 않는 불응성(refractory) $\mathrm{BPPV}$, 그리고 $\mathrm{CRP}$ 후 경과관찰되지 않은 경우는 연구에서 제외하였다. 모든 환자 에서 병력청취, 고막 검진, 신경이과적 검진 및 체위안진검사 를 하여, $\mathrm{BPPV}$ 로 진단된 경우 $\mathrm{CRP}$ 를 시행하였다. 진단 및 치료 후 주관적인 증상 및 안진이 소실될 때까지 경과 관찰 하였다.

전체 $\mathrm{BPPV}$ 환자군은 특별한 원인을 찾을 수 없고 특발성 으로 발생한 환자군(idiopathic BPPV, iBPPV), 두부 외상 후 1 개월 이내에 증상이 발생한 환자군(BPPV occurring after head and neck trauma, tBPPV) 그리고 동측의 돌발성난청과 동반된 환자군(BPPV associated with idiopathic sudden sensory neural hearing loss, sBPPV), 세 군으로 분류하였다.

\section{어지럼의 평가 및 치료}

체위안진검사를 통해 각각의 자세 변화에 따른 안진을 관 찰하였으며, 초진 시 평가 후 BPPV가 진단되면, 해당 반고리 관에 따라 $\mathrm{CRP}$ 를 시행하였다. $\mathrm{CRP}$ 의 경우 후반고리관의 경 우 Epley 수기, 수평반고리관의 경우 향지성(geotrophic) 아 형의 경우(후완 canalithiasis)는 바비큐 회전 수기(barbecue roll maneuver)와 강제지속자세(forced prolonged position), 원지성(ageotrophic) 아형인 경우(cupulolithiasis 혹은 전완 canalithiasis)는 유양돌기에 진동을 주면서 바비큐 회전 수기 (barbecue roll maneuver with mastoid oscillation), 전반고 리관의 경우 변형된 Rahko 수기를 시행하였다.,19,20) 다음 경 과관찰에서도 체위안진검사를 시행한 후, 안진이 관찰될 경 우 $\mathrm{CRP}$ 를 재시행하였다. 경과관찰은 후향적 연구로 간격은 $1 \sim 7$ 일로 다양하였다. 이러한 과정은 안진이 소실되고 증상이 회복될 때까지 반복하였고, 경과관찰에서 주관적인 증상 호 전 및 안진이 소실될 경우 완전 회복되었다고 판단하였다. 또 한, 완전 회복된 것이 확인되어 경과관찰을 종결한 이후에 다시 증상이 발생하여 내원하여 $\mathrm{BPPV}$ 로 확인된 경우 재발 
로 판단하였다.

전형적인 $\mathrm{BPPV}$ 환자인 경우는 $\mathrm{CRP}$ 를 시행하고 추가 전 정기능 검사는 시행하지 않았다. 하지만 자발 안진이 관찰되 는 등 일측성 전정기능 저하가 동반되는 것으로 의심되거나 전형적인 BPPV와는 다른 안진 양상이 있을 때, 혹은 치료를 반복적으로 시행한 후에도 호전이 없는 경우 추가적인 전정 기능평가를 시행하였다. 전체 환자 중 85 명이 온도안진검사 (bithermal caloric test), 41명이 비디오두부충동검사(video head impulse test)를 시행하였다. 온도안진검사에서 반고리 관마비(canal paresis, $\mathrm{CP}$ )가 일측 귀에서 $25 \%$ 초과하여 차 이가 나는 경우, 비디오두부충동검사에서 감소된 이득(gain, 수평반고리관 0.8 미만; 후반고리관, 전반고리관 0.7 미만)을 보이거나 명확한 현성/숨은(overt/covert) 신속안구운동(saccade)가 확인되는 경우 이상이 있다라고 판단하였다. ${ }^{21,22)}$

\section{통계 분석}

각 군 간의 진단부터 증상 및 안진이 소실되어 BPPV가 회 복될 때까지 시행한 CRP 횟수의 평균은 Student's t-test(두 군 간 비교), analysis of variance test(세 군 간 비교)로 분석 하였고, 재발률에 대해서는 chi-square test를 이용하였다. 모든 결과는 평균표준오차(standard error mean)으로 기 술하였고, 모든 통계분석은 IBM SPSS ver. 18.0(SPSS Inc., Chicago, IL, USA)을 이용하였으며, 통계적 유의 수준은 95\% 이상 $(p<0.05)$ 으로 하였다.

\section{결 과}

본 연구에 포함된 869명의 환자의 평균 연령은 56.5(19 95)세였다. 환자들의 성별은 남성 264명(30.4\%), 여성 605명 (69.6\%)이었다. BPPV 환자들은 발생한 원인에 따라 세 군으 로 분류하였을 때, 특발성으로 발생한 환자군(iBPPV)은 787 명, 두부 외상 후 발생한 $\mathrm{BPPV}$ 환자군(tBPPV)은 51명, 동측 돌발성난청과 동반된 $\mathrm{BPPV}$ 환자군 $(\mathrm{sBPPV})$ 은 31 명이었다. 두부 외상 후 발생한 $\mathrm{BPPV}$ 환자군에서 외상의 원인은 교통 사고 25명(49.0\%), 낙상 및 미끄러짐 23명(45.1\%), 그 외 폭행 등 다른 두부 충돌 3명(5.9\%) 순이었다. 두부 외상으로 인한 결과는 뇌진탕 40 명, 측두골 골절 4명, 측두골 외 기타 두개 골 골절 3 명, 경막외혈종 1 명, 지주막하출혈 3 명, 그 외 두개 내출혈 3명이었다. 이 중 3명의 경우 두개골 골절과 두개내출 혈이 동반되었다. 세 군의 구성을 비교했을 때 다른 군들에 비해 iBPPV 환자군에서 여성의 비율(남:여=28:72, 72\%)이 유의하게 높았으며 $(p<0.001)$, 나이, 고혈압, 심·뇌혈관 질환 유무는 각 군 사이에 통계적으로 유의한 차이를 보이지 않았
다(Table 1). 하지만 당뇨의 유병률은 $\mathrm{SBPPV}$ 환자군에서 다 른 군들보다 유의하게 높았고 $(p=0.048)$, 고지혈증의 경우에 는 $\mathrm{sBPPV}$ 환자군(12.9\%)이 $\mathrm{iBPPV}$ 환자군(3.6\%)보다 유의하 게 높았으나 $(p=0.008), \mathrm{tBPPV}$ 환자군(3.9\%)과는 유의한 차 이를 보이지 않았다(Table 1). 세 환자군에서 질환이 발생한 반고리관의 위치는 통계학적으로 유의한 차이는 없었으나 $(p=$ 0.318), tBPPV 환자군에서 양측성으로 발생하는 경우 $(13.7 \%$, $p<0.001)$ 와 경과관찰하는 도중 다른 반고리관으로 바뀌는 경우(canal conversion, $19.6 \%, p=0.038$ )가 다른 환자군에 비 해 유의하게 높고, $\mathrm{sBPPV}$ 환자군(16.1\%)에서 여러 개의 반고 리관에서 질환이 발생하는 경우가 유의하게 높았다 $(p<0.001$, Table 2).

\section{$\mathrm{CRP}$ 시행 횟수}

진단부터 증상이 호전되고 안진이 관찰되지 않을 때까지

Table 1. Demographics and characteristics of BPPV patients

\begin{tabular}{lcccr}
\hline & $\begin{array}{c}\text { iBPPV } \\
(\mathrm{n}=787)\end{array}$ & $\begin{array}{c}\text { tBPPV } \\
(\mathrm{n}=51)\end{array}$ & $\begin{array}{c}\text { sBPPV } \\
(\mathrm{n}=31)\end{array}$ & p value \\
\hline Age (year) & $56.56 \pm 0.52$ & $55.71 \pm 2.45$ & $58.32 \pm 2.08$ & 0.731 \\
Sex (M:F) & $28: 72$ & $53: 47$ & $58: 42$ & $<0.001$ \\
Dyslipidemia & $28(3.6)$ & $2(3.9)$ & $4(12.9)$ & 0.022 \\
DM & $66(8.4)$ & $2(3.9)$ & $6(19.4)$ & 0.048 \\
HTN & $137(17.4)$ & $6(11.8)$ & $4(12.9)$ & 0.483 \\
CVA, CVD & $17(2.2)$ & $1(2.0)$ & $2(6.5)$ & 0.291 \\
\hline
\end{tabular}

Data are presented as the mean \pm standard error of mean or n (\%). BPPV: benign paroxysmal positional vertigo, DM: diabetes mellitus, HTN: hypertension, CVA: cerebrovascular accident, CVD: cardiovascular disease, iBPPV: idiopathic BPPV, tBPPV: BPPV occurring after head trauma, sBPPV: BPPV associated with idiopathic sudden sensory neural hearing loss

Table 2. Clinical characteristics of BPPV groups

\begin{tabular}{lcccr}
\hline & $\begin{array}{c}\text { iBPPV } \\
(\mathrm{n}=787)\end{array}$ & $\begin{array}{c}\text { tBBPV } \\
(\mathrm{n}=51)\end{array}$ & $\begin{array}{l}\text { sBPPV } \\
(\mathrm{n}=31)\end{array}$ & p value \\
\hline $\begin{array}{l}\text { Direction } \\
\text { R:L:both }\end{array}$ & $410: 361: 16$ & $28: 16: 7$ & $18: 13: 0$ & $<0.001$ \\
Involved canal & & & & 0.318 \\
AC & $26(3.3)$ & $0(0)$ & $1(3.2)$ & \\
PC & $394(50.1)$ & $34(66.7)$ & $15(48.4)$ & \\
HC (canalithiasis) & $191(24.3)$ & $9(17.6)$ & $7(22.6)$ & \\
HC (cupulolithiasis) & $154(19.6)$ & $7(13.7)$ & $3(9.7)$ & \\
Multiple canals & $22(2.8)$ & $1(2.0)$ & $5(16.1)$ & $<0.001$ \\
Number of CRP & $1.40 \pm 0.03$ & $2.04 \pm 0.24$ & $2.45 \pm 0.36<0.001$ \\
Canal conversion & $49(6.2)$ & $10(19.6)$ & $4(12.9)$ & 0.038 \\
Recurrence & $115(14.6)$ & $9(17.6)$ & $5(16.1)$ & 0.822 \\
\hline Data ar & & & &
\end{tabular}

Data are presented as the mean \pm standard error of mean or $\mathrm{n}$ (\%). BPPV: benign paroxysmal positional vertigo, AC: anterior canal, PC: posterior canal, HC: horizontal canal CRP: canalith repositioning procedure, iBPPV: idiopathic BPPV, †BPPV: BPPV occurring after head trauma, sBPPV: BPPV associated with idiopathic sudden sensory neural hearing loss 
시행한 $\mathrm{CRP}$ 횟수는 $\mathrm{iBPPV}, \mathrm{tBPPV}, \mathrm{sBPPV}$ 환자군에서 각각 $1.40 \pm 0.03$ 회, 2.04 \pm 0.24 회 그리고 $2.45 \pm 0.36$ 회였다(Fig. 1). 세 군 간에 $\mathrm{CRP}$ 시행 횟수를 비교했을 때 $\mathrm{iBPPV}$ 환자군에 서 통계적으로 유의하게 다른 그룹에 비해 적었다 $(p<0.001)$. 하지만 $\mathrm{sBPPV}$ 와 $\mathrm{tBPPV}$ 환자군 사이에서 회복까지의 $\mathrm{CRP}$ 시행 횟수는 차이가 없었다 $(p=0.168)$.

\section{재발률}

회복 후 BPPV가 재발하는 비율을 보면 iBPPV, tBPPV, sBPPV 환자군에서 각각 $14.6 \%(115 / 787), 17.7 \%(9 / 51)$, 그리 고 16.2\%(5/31)였다(Fig. 2). 두부외상 후 BPPV군이 가장 높 았지만 세 군 사이에 재발률은 통계적으로 유의한 차이가 없 었다 $(p=0.822)$.

\section{온도안진검사과 비디오두부충동검사 이상}

전체 환자에서 온도안진검사는 85 명, 비디오두부충동검사 는 41 명이 시행하였고, 온도안진검사 결과의 이상은 $38.8 \%$ (33/85), 비디오두부충동검사 결과의 이상은 73.2\%(30/41)의 환자에서 관찰되었다. 각 군별로 살펴보면 온도안진검사 결과 의 이상은 $\mathrm{iBPPV}, \mathrm{tBPPV}, \mathrm{sBPPV}$ 환자군에서 각각 25 명, 4명, 4명이었고, 비디오두부충동검사 결과의 이상은 각각 19명, 2 명, 9명이었다. 온도안진검사에서 이상이 있는 군의 $\mathrm{CP}$ 는 병변 측

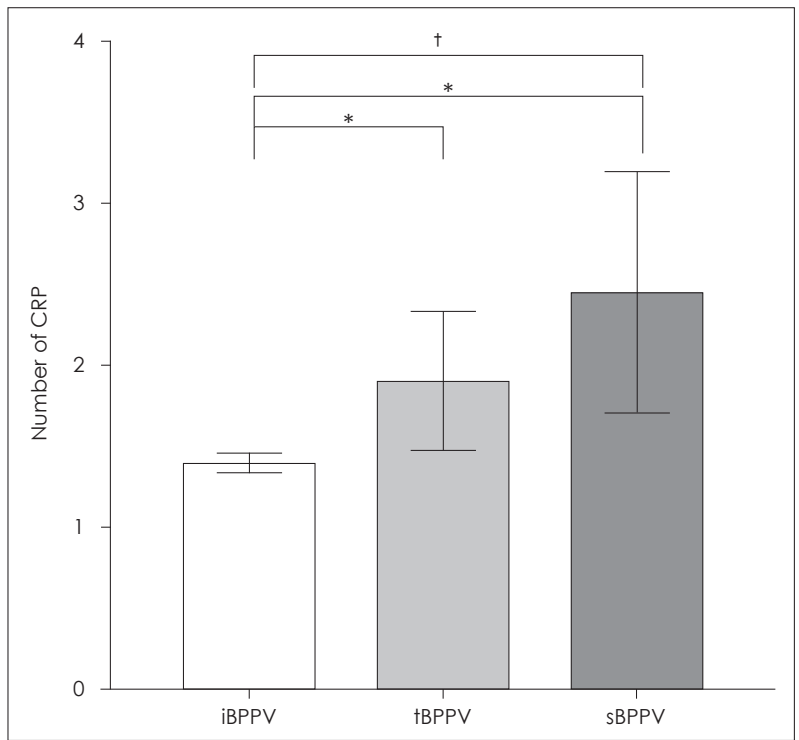

Fig. 1. Number of CRP performed to achieve successful reposition (mean with $95 \%$ confidence interval). The mean number of CRPs needed for successful repositioning in the iBPPV $(1.40 \pm 0.03)$ group was less than the tBPPV (2.0 \pm 0.24$)$ and sBPPV (2.45 \pm 0.36$)$ groups significantly. There was no difference between the tBPPV and SBPPV groups. ${ }^{*} p<0.001$, Student's t-test; $+p<0.001$, analysis of variance test. CRP: canalith repositioning procedure, iBPPV: idiopathic BPPV, tBPPV: BPPV occurring after head trauma, sBPPV: BPPV associated with idiopathic sudden sensory neural hearing loss, BPPV: benign paroxysmal positional vertigo.
으로 평균 39.8\%(26 97)였다. 두 검사 결과를 바탕으로 전정 기능검사에서 이상이 있는 군과 정상인 군을 나누어 비교해 보았을 때, 두 군의 회복까지 필요한 $\mathrm{CRP}$ 횟수와 재발률은 통계적으로 유의한 차이가 없었다(CRP 횟수: $1.63 \pm 0.85 \mathrm{VS}$. $1.46 \pm 0.98, p=0.345$; 재발률: $16.7 \%$ vs. $14.8 \%, p=0.775)$.

\section{고 찰}

$\mathrm{BPPV}$ 의 경우 말초성 어지럼 질환 중에 가장 흔하게 발생 하는 질환으로, 특발성으로 가장 많이 발생하고, 그 다음으로 는 두부 외상에 의해 많이 발생한다고 알려져 있다. ${ }^{23)}$ 그 외에 도 돌발성난청과 동반되어 함께 발생하기도 한다. 이전의 연 구들에 따르면 일반적으로 특발성으로 발생하는 경우보다 두부 외상에 의해 발생하거나, 돌발성난청과 동반되어 BPPV 가 발생하는 경우 회복까지의 기간이 오래 걸리며, 더 높은 재 발률을 보인다는 보고가 많았다.,15-17) 특발성 BPPV 환자에 비해 경미한 두부 외상 후 발생한 $\mathrm{BPPV}$ 환자군에서 치료 결 과의 예후가 더 좋지 않으며, 여러 반고리관에서 발생하는 경 우가 많다고 보고하였고, ${ }^{15)} \mathrm{BPPV}$ 를 동반한 돌발성난청 환자 연구에서는 돌발성난청과 동반된 $\mathrm{BPPV}$ 환자군에서 회복될 때까지 시행한 $\mathrm{CRP}$ 횟수(4.3회)가 특발성 환자군(1.3회)보다 많았고, 동시에 여러 반고리관에서 BPPV가 발생하였다.) 반 면에 다른 결과를 보인 연구들도 있었는데, BPPV 환자 1378명 을 후향적으로 분석한 연구에서는 외상 후 BPPV군(118명)과 특발성 BPPV군 사이에 회복까지의 기간이나 방문 횟수에서

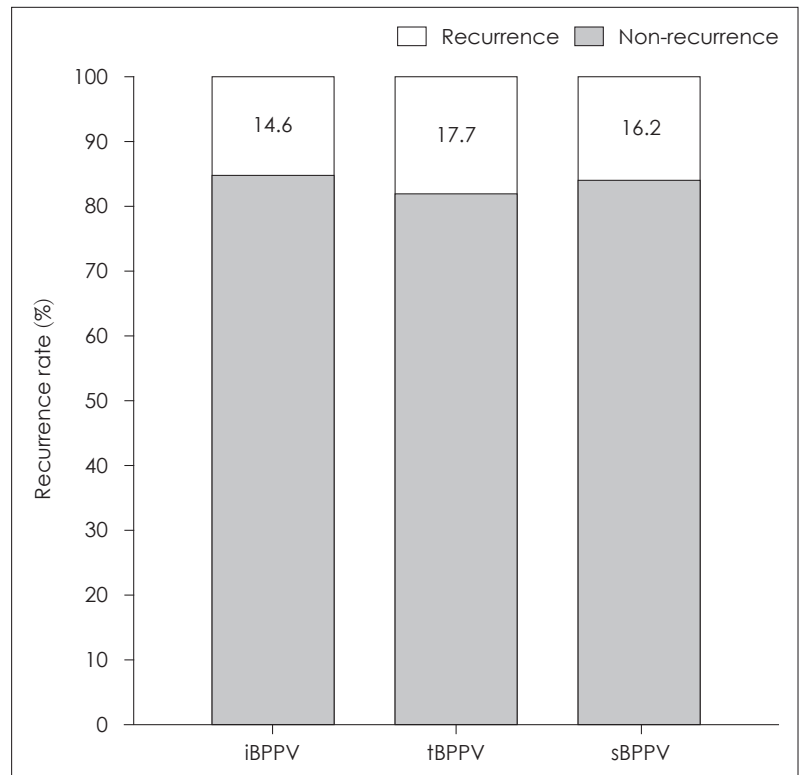

Fig. 2. Recurrence rate of three groups. iBPPV: idiopathic BPPV, tBPPV: BPPV occurring after head trauma, sBPPV: BPPV associated with idiopathic sudden sensory neural hearing loss, BPPV: benign paroxysmal positional vertigo. 
유의한 차이를 보이지 않았다. ${ }^{24)}$ 또한 두 군의 재발률을 비교 하였을 때도 통계적으로 의미 있는 차이를 보이지 않았다. ${ }^{24,25)}$ 내이 질환에 의해 발생한 이차성 BPPV에 대한 연구를 보면, 특발성 BPPV 환자군(1469명)과 메니에르병과 동반된 BPPV 군(112명)을 비교하였을 때 두 군에서 치료까지의 기간, 치료 횟수 및 재발률에서 유의한 차이를 보이지 않았다는 보고도 있었다. ${ }^{26)}$ 돌발성난청에 동반된 $\mathrm{BPPV}$ 의 경우 특발성 $\mathrm{BPPV}$ 와 임상양상이 다를 수 있다. 한 연구에서는 돌발성난청과 함께 진단된 후반고리관 $\mathrm{BPPV}$ 인 경우 환자의 심혈관계 관련된 기 저질환 혹은 항응고제 및 항혈소판제 복용여부와 관련 있을 수 있고, 이로 인해 내이에서 출혈이 발생한 후 응고되어 혈전 이 형성될 수 있으며, 발생한 혈전이 반고리관에서 이석과 같 은 작용을 하여 어지럼증을 유발시킬 수 있다고 보고하였다. ${ }^{2)}$ $\mathrm{BPPV}$ 의 기전이 다르다면 임상양상과 예후에도 차이가 있을 것이라 예상할 수 있다.

본 연구에서는 특발성 $\mathrm{BPPV}$ 와 이차성 $\mathrm{BPPV}$ 중 대표적인 두부 외상 후 $\mathrm{BPPV}$, 그리고 돌발성난청과 함께 동반된 $\mathrm{BPPV}$ 의 임상양상과 예후를 비교하였다. 일반적으로 $\mathrm{BPPV}$ 의 경우 남성보다 여성에서 1.5 배 발병률이 높다고 알려져 있다. ${ }^{27)}$ 본 연구에서는 $\mathrm{iBPV}$ 환자군은 여성의 발병률이 높았으나, $\mathrm{tBPPV}$ 와 $\mathrm{sBPPV}$ 환자군에서는 오히려 남성의 비율이 더 높았고 세 군 사이에 유의한 차이를 보였다. BPPV 발생 반고리관은 특 발성인 경우 후반고리관에서 가장 흔하고, 돌발성난청과 동반 될 때에도 후반고리관에서 발생하는 경우가 가장 많다고 알 려져 있다. ${ }^{27-29)}$ 이 연구에서도 이전 보고들과 같이 세 군 모두 에서 후반고리관 BPPV가장 많았으나, 각 군 간에 유의한 차 이는 보이지는 않았다 $(p=0.318)$. 진단 후 회복될 때까지 시행 한 $\mathrm{CRP}$ 의 횟수는 $\mathrm{iBPPV}$ 환자군에서 다른 군에 비해 통계적 으로 유의하게 적었다. 각 군에서의 재발률을 비교하였을 때, tBPPV 환자군에서 재발률이 다른 군에 비해 높았으나, 통계 적으로 유의한 차이를 보이지는 않았다. 온도안진검사와 비디 오두부충동검사 결과의 이상은 재발률과 회복까지의 CRP 횟 수와는 통계적으로 유의한 결과를 보이지 않았다. 전체 군에 비해 검사를 시행한 환자가 적어 결과에 포함되지 않았지만 온도안진검사를 시행한 85 명에서 $\mathrm{CP}$ 이상이 확인된 33명의 환자에서 $\mathrm{CP}$ 수치와 회복에 필요한 $\mathrm{CRP}(1.63$ 회 $)$ 상관관계를 살펴보았을 때, 이는 통계적으로 유의하지 않았다 $(p=0.345)$.

이 연구에서는 후향적으로 의무기록을 분석한 연구이기 때 문에 원하는 모든 임상 정보를 얻지 못하였을 수 있고, 분석 및 결과 해석에 한계가 있다. 미처 확인되지 않은 기저질환이 존재할 수도 있으며, 분석에 포함된 환자에게 MRI나 전정기 능평가를 모두 시행하지 않아 원인 질환이 배제되지 않았을 가능성도 있다. 그리고 중요한 결과변수인 CRP 횟수를 비교
하는데 있어서도 환자들의 경과관찰 기간이 일정하지 않아 해석에 주의를 해야 한다. 일반적으로 외래환자의 경우 일주 일 단위로 경과관찰을 시행하였으나, 환자가 주관적으로 느 끼는 증상이 심해 일찍, 자주 내원한 경우 시행한 CRP 횟수 가 과평가 되었을 가능성이 있다. 그리고 처음 진단 후 $\mathrm{CRP}$ 를 1 회 시행 후 호전된 환자의 경우, 추가 방문하지 않아 경과관 찰이 누락되어서 예후가 좋은 $\mathrm{BPPV}$ 환자들이 연구에 제외 되었을 가능성 역시 존재한다. 그리고 2020년 5월까지 내원한 환자를 대상으로 하여 경과관찰 기간이 1년이 되지 않는 환 자도 일부 포함되어 있어 재발률에 영향을 줄 수 있다. 또한, 본 연구기관에서 모든 $\mathrm{BPPV}$ 환자에서 온도안진검사 및 비디 오두부충동검사 등 전정기능검사를 일률적으로 시행하지 않 았기 때문에 여러 검사를 종합하여 분석하지 못하였다. 전형 적인 $\mathrm{BPPV}$ 인 경우는 $\mathrm{CRP}$ 를 시행 후 전정기능검사를 시행하 지 않는 경우가 대부분이다. 하지만 자발 안진이 관찰되는 등 일측성 전정기능 저하가 동반되는 것으로 의심되거나 전형적 인 BPPV와는 다른 안진 양상이 있을 때, 혹은 치료를 수 차 례 시행하여도 호전이 없는 경우 추가적인 전정기능평가를 시행하였다. 따라서 모든 환자군에서 시행을 하지 않아, 이상 소견이 있음에도 검사를 시행하지 않아 평가하지 못한 부분 이 발생하여, 단정적으로 결과를 해석하는 데 제한점이 있다.

그럼에도 불구하고 본 연구는 $\mathrm{BPPV}$ 의 발생 원인에 따라 세 군으로 나누어 상대적으로 큰 규모의 환자군을 분석하였 고, 이차성 $\mathrm{BPPV}$ 중 주요 비중을 차지하는 외상성 $\mathrm{BPPV}$ 와 내이 질환 중 대표적인 돌발성난청에 동반된 $\mathrm{BPPV}$ 의 임상양 상을 함께 비교해보았다는 것에서 의미가 있다. 이차성 $\mathrm{BPPV}$ ( $\mathrm{tBPPV}$ 와 sBPPV군)인 경우 성별 비중이 여성에 호발하는 특 발성 $\mathrm{BPPV}$ 와 유의한 차이를 보였고, 특발성 $\mathrm{BPPV}$ 군보다 치 료까지 필요한 $\mathrm{CRP}$ 횟수가 유의하게 많아 나쁜 예후를 보였 다. 각 원인에 따른 재발률에는 두부 외상 후 발생한 BPPV 환자에서 가장 높았으나, 통계적으로는 유의미한 차이를 보이 지 않았다. 두부외상 $\mathrm{BPPV}$ 환자군에서 양측성 발생과 치료 중 다른 반고리관으로의 이환이 유의하게 높았다. 이러한 결 과들은 임상에서 $\mathrm{BPPV}$ 환자를 진료와 치료에 도움을 주는 정보가 될 것이다.

\section{Acknowledgments}

None.

\section{Author Contribution}

Conceptualization: Joo Hyun Park. Data curation: Wook Jang, Jung-Woo Sang, Sang Woo Kim, Do Hyung Kim. Formal analysis: Joo Hyun Park, Bo Hae Kim. Investigation: Wook Jang, Jung-Woo Sang, Do Hyung Kim. Methodology: Wook Jang, Joo Hyun Park. Supervision: Chang Gun Cho, Seok-Won Park, Yun-Sung Lim. Validation: Joo Hyun Park. Visualization: Wook Jang. Writing—origi- 
nal draft: Wook Jang, Joo Hyun Park. Writing—review \& editing: Joo Hyun Park, Chang Gun Cho.

\section{ORCIDs}

Joo Hyun Park

https://orcid.org/0000-0002-1499-3328

Wook Jang

\section{REFERENCES}

1) Lee JH, Song MH, Park JW, Ko KM, Shim DB. Clinical manifestations of benign paroxysmal positional vertigo after head trauma. Korean J Otorhinolaryngol-Head Neck Surg 2015;58(12): 836-40.

2) Kim CH, Shin JE, Park HJ, Koo JW, Lee JH. Concurrent posterior semicircular canal benign paroxysmal positional vertigo in patients with ipsilateral sudden sensorineural hearing loss: Is it caused by otolith particles? Med Hypotheses 2014;82(4):424-7.

3) Kim JS, Zee DS. Clinical practice. Benign paroxysmal positional vertigo. N Engl J Med 2014;370(12):1138-47.

4) Kim MB, Ban JH. Benign paroxysmal positional vertigo accompanied by sudden sensorineural hearing loss: A comparative study with idiopathic benign paroxysmal positional vertigo. Laryngoscope 2012;122(12):2832-6.

5) Karlberg M, Hall K, Quickert N, Hinson J, Halmagyi GM. What inner ear diseases cause benign paroxysmal positional vertigo? Acta Otolaryngol 2000;120(3):380-5.

6) Mandalà M, Santoro GP, Awrey J, Nuti D. Vestibular neuritis: Recurrence and incidence of secondary benign paroxysmal positional vertigo. Acta Otolaryngol 2010;130(5):565-7.

7) Baloh RW, Honrubia V, Jacobson K. Benign positional vertigo: Clinical and oculographic features in 240 cases. Neurology 1987; 37(3):371-8.

8) Ahn SK, Jeon SY, Kim JP, Park JJ, Hur DG, Kim DW, et al. Clinical characteristics and treatment of benign paroxysmal positional vertigo after traumatic brain injury. J Trauma 2011;70(2):442-6.

9) Chen G, Li Y, Si J, Zhao X, Zhang T, Dai X, et al. Treatment and recurrence of traumatic versus idiopathic benign paroxysmal positional vertigo: A meta-analysis. Acta Otolaryngol 2019;139(9): 727-33.

10) Gordon CR, Levite R, Joffe V, Gadoth N. Is posttraumatic benign paroxysmal positional vertigo different from the idiopathic form? Arch Neurol 2004;61(10):1590-3.

11) Hughes CA, Proctor L. Benign paroxysmal positional vertigo. Laryngoscope 1997;107(5):607-13.

12) West N, Hansen S, Bloch SL, Møller MN, Klokker M. Benign paroxysmal positional vertigo treatment. Ugeskr Laeger 2017; 179(23):V11160784.

13) Instrum RS, Parnes LS. Benign paroxysmal positional vertigo. Adv Otorhinolaryngol 2019;82:67-76.

14) Bhattacharyya N, Gubbels SP, Schwartz SR, Edlow JA, El-Kashlan $\mathrm{H}$, Fife T, et al. Clinical Practice Guideline: Benign paroxysmal positional vertigo (update). Otolaryngol Head Neck Surg 2017;

156(3_suppl):S1-47.

15) Balatsouras DG, Koukoutsis G, Aspris A, Fassolis A, Moukos A, Economou NC, et al. Benign paroxysmal positional vertigo secondary to mild head trauma. Ann Otol Rhinol Laryngol 2017;126(1):54-60.

16) Lee NH, Ban JH. Is BPPV a prognostic factor in idiopathic sudden sensory hearing loss? Clin Exp Otorhinolaryngol 2010;3(4):199202.

17) Pirodda A, Raimondi MC, Ferri GG. Idiopathic sudden sensorineural hearing loss and comorbid benign paroxysmal positional vertigo: Some pathogenic additional considerations. Otol Neurotol 2012; 33(5):895; author reply 895-6.

18) von Brevern $M$, Bertholon $P$, Brandt $T$, Fife $T$, Imai $T$, Nuti $D$, et al. Benign paroxysmal positional vertigo: Diagnostic criteria. J Vestib Res 2015;25(3-4):105-17.

19) Bhattacharyya N, Gubbels SP, Schwartz SR, Edlow JA, El-Kashlan H, Fife T, et al. Clinical Practice Guideline: Benign paroxysmal positional vertigo (update) executive summary. Otolaryngol Head Neck Surg 2017;156(3):403-16.

20) Kim SH, Jo SW, Chung WK, Byeon HK, Lee WS. A cupulolith repositioning maneuver in the treatment of horizontal canal cupulolithiasis. Auris Nasus Larynx 2012;39(2):163-8.

21) Yang CJ, Lee JY, Kang BC, Lee HS, Yoo MH, Park HJ. Quantitative analysis of gains and catch-up saccades of video-head-impulse testing by age in normal subjects. Clin Otolaryngol 2016;41(5):532-8.

22) Jongkees LB, Maas JP, Philipszoon AJ. Clinical nystagmography. A detailed study of electro-nystagmography in 341 patients with vertigo. Pract Otorhinolaryngol (Basel) 1962;24:65-93.

23) Józefowicz-Korczyńska M, Pajor A, Skóra W. Benign paroxysmal positional vertigo in patients after mild traumatic brain injury. Adv Clin Exp Med 2018;27(10):1355-9.

24) Luryi AL, LaRouere M, Babu S, Bojrab DI, Zappia J, Sargent EW, et al. Traumatic versus idiopathic benign positional vertigo: Analysis of disease, treatment, and outcome characteristics. Otolaryngol Head Neck Surg 2019;160(1):131-6.

25) Di Cesare T, Tricarico L, Passali GC, Sergi B, Paludetti G, Galli J, et al. Traumatic benign paroxysmal positional vertigo: Personal experience and comparison with idiopathic BPPV. Int J Audiol 2020:1-5.

26) Luryi AL, Lawrence J, Bojrab D, LaRouere M, Babu S, Hong R, et al. Patient, disease, and outcome characteristics of benign paroxysmal positional vertigo with and without Meniere's disease. Acta Otolaryngol 2018;138(10):893-7.

27) Yetiser S, Ince D. Demographic analysis of benign paroxysmal positional vertigo as a common public health problem. Ann Med Health Sci Res 2015;5(1):50-3.

28) Pogson JM, Taylor RL, Young AS, McGarvie LA, Flanagan S, Halmagyi GM, et al. Vertigo with sudden hearing loss: Audiovestibular characteristics. J Neurol 2016;263(10):2086-96.

29) Lee JY, Lee YW, Chang SO, Kim MB. Vestibular function analysis of sudden sensorineural hearing loss with dizziness. J Vestib Res 2020;30(3):203-12. 